\title{
EXPERIMENTALLY VALIDATED NUMERICAL ANALYSIS OF REINFORCED CONCRETE SLAB-COLUMN CONNECTIONS SUBJECTED TO PUNCHING SHEAR
}

\author{
S.C. Floruț ${ }^{\text {a }}$, D.A. Popescu ${ }^{\text {a }}$, V. Stoian ${ }^{\text {a }}$, D. Dan ${ }^{\text {a }}$, T. Nagy-György ${ }^{\text {a }}$, V. Todea ${ }^{\text {a }}$ \\ ${ }^{a}$ Faculty of Civil Engineering, Politehnica University Timisoara, 2nd T. Lalescu, 300223 Timisoara, Romania \\ E-mails:*codrut.florut@upt.ro, dan.popescu@student.upt.ro, valeriu.stoian@upt.ro, daniel.dan@upt.ro, tamas.nagy-gyorgy@upt.ro, \\ viorel.todea@student.upt.ro
}

Received: 24.07.2020 / Accepted: 31.07.2020/ Revised: 19.08.2020 / Available online: 15.12.2020

DOI: 10.2478/jaes-2020-0019

KEY WORDS: reinforced concrete, flat slabs, punching shear, strengthening, numerical modelling.

\begin{abstract}
:
The paper presents the results of experimental investigations and numerical analyses performed on reinforced concrete flat slabs. Two tests were carried out on two flat slab specimens designed without specific shear reinforcement. The present paper deals only with the experimental behaviour and numerical modelling of such slabs, this representing the initial part of a larger study which aims to evaluate the shear capacity of such deficient slabs resulted from faulty design or execution and to identify viable and efficient strengthening solutions. ATENA finite element software package was used to numerically model the behaviour of the specimens. A very good agreement was achieved between the results of experimental investigations and numerical modelling with deviations of $0.2 \%$ in terms of maximum load carrying capacity and of $7 \%$ in terms of corresponding displacement. The specimens were able to carry loads of more than $950 \mathrm{kN}$, larger than those evaluated using designated Eurocodes, displaying a safety factor of 2.72.
\end{abstract}

\section{INTRODUCTION}

The numerical, analytical, and experimental research discussed in this paper represent initial results from a wider study which deals with the punching shear behaviour of Reinforced Concrete (RC) slab-column connections and with the structural strengthening of such elements. While the authors propose a series of strengthening solutions, the results included in this paper are related exclusively to experimental behaviour numerical analysis, and analytical assessment of bare RC flat slabs without specific shear reinforcement, representing deficient slabs resulted from faulty design or execution.

The use of RC flat slabs provides a series of advantages for developers and clients, but it also leads to some structural issues, especially when considered for buildings placed in seismic areas. The main advantages of this system refer to high execution speed and an increased versatility in terms of partitioning. The main disadvantage of the system in seismic areas is represented by the perspective of brittle failure of the flat slabs under seismic loads due to punching shear. This failure mode is usually sudden, brittle, and catastrophic, as a local failure of the slab-column connection can initiate wider damage to the whole structure (Gardner, 2002). In Western Europe and non-seismic areas of the United States of America, the system is extensively applied for mid- and high-rise buildings, at the same time representing the most efficient and cheap solution for regular reinforced concrete floor systems (PCA Association, 2005).
RC flat slab systems were first introduced at the end of $19^{\text {th }}$ Century and start of the $20^{\text {th }}$ Century due to research by Hill and Turner (first flat slabs executed between 1899 and 1901) in United States of America and Maillart in Europe who led a series of experimental programs between 1900 and 1908. Based on Maillart's research the first storage building having implemented this system was constructed in Zurich in 1910. In the same period, Russian engineer Lolelit also designed a series of slabs resting directly on columns, thus contributing to the development of the system. The similarity between all the solutions applied in the emerging phase of the system lies in the fact that all slabs had large areas of drop-panels at the slabcolumn connections. Even though tensioned reinforcement was designed using different analytical approaches and led to varying reinforcement ratios, none of these systems considered specific shear (punching shear) reinforcement (Bartolac, 2015) and (Kierdorf, 2006)

First types of reinforcement against punching were provided in the shape of inclined bars and stirrups. The system which is now in regular use for reinforcement against punching was first introduced in 1970 s by Andrä, a German researcher. It comprises of a set of vertical bars with anchoring heads aligned along a single metal strip (Bartolac, 2015).

The first theoretical analysis evaluating the forces and stresses that develop in beamless slabs was performed by Westergaard and Slater in 1921.

* Corresponding author: Sorin-Codruț Floruț, Lecturer PhD Eng., Faculty of Civil Engineering, Politehnica University Timisoara, 2nd T. Lalescu, 300223 Timisoara, Romania, e-mail: codrut.florut@upt.ro. 
Finite differences method was used as the authors considered various loading cases and various contributions of the stiffness of columns and drop panels (Westergaard, 1921). Later models developed by Kinnunen and Nylander in 1960 (Kinnunen, 1960) and Alexander and Simmons in 1986 (Alexander, 1986) have been proved to be quite accurate in predicting the punching shear capacity of slabs (Said, 2012). Although Kinnunen and Nylander's theory was developed for slabs not specifically reinforced against punching, it served as the basis to numerous researchers which were developing behaviour models for slabs reinforced against punching action (Bartolac, 2015). The first set of coded recommendations was given in the ACI Code for the design of reinforced concrete structures published in 1925 (Furst, 1997).

One of the most advanced theoretical approaches in the design of flat slabs against punching is the one based on critical shear crack theory (Muttoni, 1991), (Muttoni, 2008), (Fernández Ruiz, 2009), (Lips, 2012). This was also implemented in the 2010 published Model Code issued by fib (Fédération Internationale du béton). According to this theory, the punching shear strength of slabs depends on the slab inclination (rotation) due to load, and the slab stiffness defined through bending strength.

Regular design approaches consider the use of specific reinforcement against punching, usually in the shape introduced by Andrä in the 1970s (see above). Recently, the authors of the current paper have however identified a worrying tendency of designers to exclude this specific reinforcement from the design stage. This approach is usually related to pressure from execution companies which consider that this reinforcement is mounted in a cumbersome manner (especially in a flab slab inside a multi-storey building placed in seismic areas with high reinforcement congestion at the slab-column connection) and is expensive. This tactic is also partially supported by the knowledge that overcoming punching shear failure of a slabcolumn connection can usually be done by applying one of these six solutions: 1) increase the thickness of the slab, 2) increase the supporting area for the slab i.e. increase the crosssection of columns, 3) introduce drop panels, 4) use higherstrength concrete, 5) use higher-strength steel or increased area for tensioned reinforcement and 6) provide additional shear reinforcement inside the slab, around the supporting area. However, while the first five solutions mentioned before result in an increase in punching strength, the only solution that also leads to increased ductility is the sixth one, and this is a very important aspect in seismic areas.

The issue of RC flat slabs with deficient carrying capacity, mainly against punching shear, may frequently appear due to errors in structural design (including inappropriate choices for location of ducts or other openings in the vicinity of slabcolumn connection), poor execution or due to changes in functionality over the years (changes which usually lead to increased load demands and thus higher stresses). Consequently, high interest should be paid to finding and implementing viable strengthening solutions, to overcome these deficiencies of the system (Meisami, 2013).

Considering all the above, the key objective of the research was to propose viable strengthening solutions and to investigate whether they can increase the load capacity of slabs in comparison to that of the reference specimens. The second objective was to identify the behaviour of flat slabs without punching reinforcement. Thirdly, the study aims to identify numerical solutions which provide good accordance to the experimental results and perform a parametric study to further enhance the knowledge in the field.

The present paper addresses solely the issues related to the experimental behaviour, numerical analysis, and analytical assessment of flat slabs without punching shear reinforcement.

\section{PUNCHING SHEAR IN FLAT SLABS}

Regarding their constructional details, RC flat slabs usually fall into one of the following four categories: 1) Simple flat slabs, 2) Flat slab with drop panels, 3) Flat slab with column heads and 4) Flat slab with both drop panels and column heads. The general configuration of "Simple flat slabs" and "Flat slab with both drop panels and column heads" is identifiable in Figure 1.
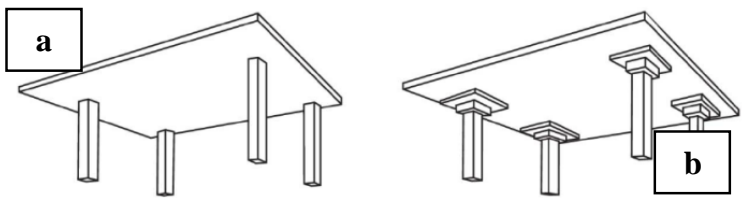

Figure 1. Flat slabs (Popescu, 2018)

\section{$(a, b$. Simple flat slab, Flat slab with both drop panels} and column heads)

Supporting the slab directly on columns or walls leads to the need of transferring relatively high loads onto a rather small concrete area. The governing element which prevails the design of this load transfer system is thus the slab-column connection, as the high stress concentration in this area could lead to punching shear failure (Bartolac, 2015). Obviously, for a slab of a given thickness, the system which is most susceptible to high stress concentration in concrete and punching failure is the "Simple flat slab" one, as the supporting area for the slab is the smallest possible, no increase in thickness being available.

Punching failure is characterised by a brittle failure, followed by a sudden drop of the load-carrying capacity, without relevant signs or warnings prior to collapse. The failure is trigged by cracks which appear inside the slab in the immediate area of the supporting element and then develop and propagate towards the edges of the slab at angles usually varying between 20 and 45 degrees, leading to punching failure of the slab-column connection. This failure mechanism increases the sensitivity of such specimens to imposed deformations and allows for very limited stress redistribution.

In most situations, the local failure of a slab-column connection leads to failure adjacent joints, causing a progressive collapse of floors or even the entire building. Even if punching shear failure does not occur, flat slabs do not represent a very efficient structural system for energy dissipation, which is a highly important structural characteristic in terms of seismic performance (Popescu, 2018). Thus, this type of failure must be avoided, the design requiring extremely careful approach. Moreover, it must be avoided even further when considering flat slabs in seismic areas with the subsequent requirements in lateral deformation capacity of the slab-column connection.

The crucial parameters which determine the punching shear capacity of a slab-column connection are: compressive and tensile strength of concrete, reinforcement ratios and 
configuration of reinforcement, cross-sectional shape and dimensions of the supports (columns), effective depth of the slab and configuration and dimensions of openings inside the critical punching perimeter. A typical failure of a slab-column connection under punching shear is illustrated in Figure 2.

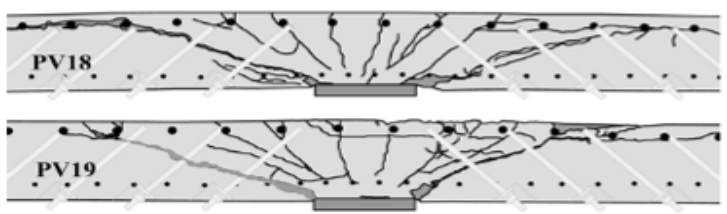

Figure 2. Failure of a RC flat slab under punching shear failure (Fernandez Ruiz, 2011)

\section{STRENGTHENING OF DEFICIENT FLAT SLABS}

Available solutions for strengthening of such deficient RC flat slabs in punching fall mainly into one of the following four groups: 1) changing of the configuration of the slab-column connection, 2) post-installing transversal reinforcement, 3) increasing the capacity of the slab in the tensioned area and 4) increasing the effective depth of the RC slab (Popescu, 2018). However, excluding the solutions that completely transform the structural system, most approaches follow the same procedure that consists in applying a post-installed system that would partially reproduce the specific punching shear reinforcement that should have been installed before casting the concrete or that has been under-evaluated.

Some researchers approached solutions with more applicability and reduced workmanship such as the use of inclined shear reinforcement installed within existing slabs by drilling holes only from the soffit of the slab and by bonding it with highperformance epoxy adhesive proposed by (Fernandez Ruiz, 2010) or the use of post-installed steel bolts and flexible washers (Topuzi, 2017) or the use of a combined solution based on Carbon Fibre Reinforced Polymer (CFRP) for increasing flexural capacity and Embedded-Through-Section FibreReinforced-Polymer (ETS-FRP) reinforcement for increasing the punching shear capacity (Barros, 2017).

The usually applicable solutions can be identified in Figure 3, Figure 4 and Figure 5. These solutions consider the increase of cross-sectional area of vertical elements (and thus of supporting area for the slabs) in the case of Figure 3 (a) and (b), mounting new reinforcement and casting a new layer of concrete connected to the existing one Figure 4 (a) or gluing new flexural reinforcement made of steel or even Fibre Reinforced Polymers FRPs Figure 4 (b), mounting of post-installed vertical or inclined reinforcement Figure 5 (e) and (f) (Fernandez Ruiz, 2010). Obviously, each of these techniques clearly leads to some advantages and disadvantages and could be considered viable or unfitting from one application to another.
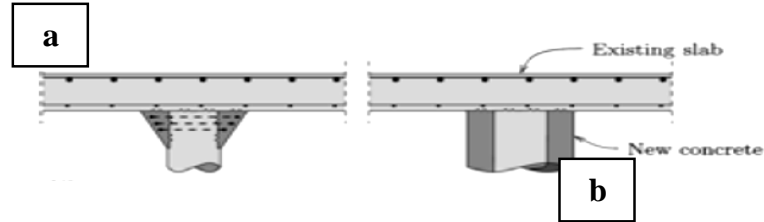

Figure 3. Usual applicable solutions for strengthening of deficient flat slabs against punching (Fernandez Ruiz, 2011)

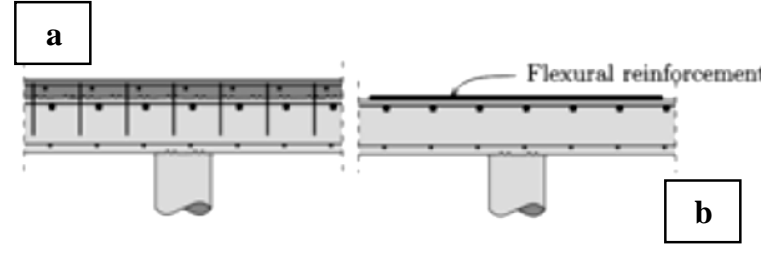

Figure 4. Usual applicable solutions for strengthening of deficient flat slabs against punching (Fernandez Ruiz, 2011)

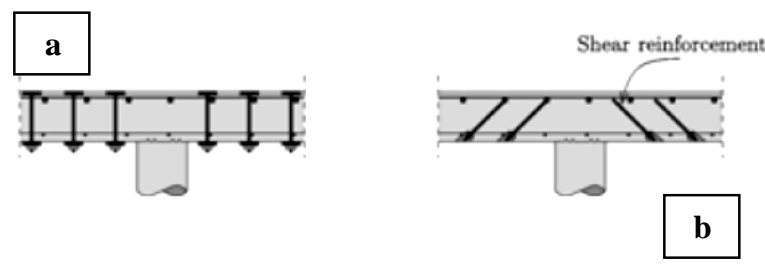

Figure 5. Usual applicable solutions for strengthening of deficient flat slabs against punching (Fernandez Ruiz, 2011)

\section{DETAILS OF EXPERIMENTAL PROGRAM}

As previously mentioned, the major aim of the proposed research is to identify the behaviour and performance of RC flat slabs strengthened by using a new technique. The authors' proposal represents an alternative solution to those already available, based on using Fibre-Reinforced-CementitiousMortars (FRCM) applied as a thin layer of overcast material The solution is based on the idea that once the new high tensile strength material is applied, a similar effect to those of reinforced concrete overcasting (see solution "a" in Figure 4) can be achieved, without the need of thoroughly connecting new reinforcement with the existing concrete. In this way, the interventions would be a lot less demanding in terms of labour.

Other two solutions consider the use of post-installed vertical reinforcement (one solution with STEEL and the other using ETS-FRP) embedded in section using high strength epoxy resins. Finally, the latter two solutions were combined with the one based on FRCM. The experimental program consisted in testing twelve flat slabs up to failure. While two of the specimens served as reference and were tested in as-built configuration, on the other 10 specimens five different strengthening solutions were applied (i.e. two specimens tested for each proposed strengthening system). The strengthening solutions and the combinations of the methods can be observed inside Figure 6 and Figure 7.

The denomination of each test is identifiable inside Figure 6 and Figure 7. For identifying all tests, the designation of "PS" was used (standing for "Punching Shear"). Tests labels on bare elements were followed by the letter "R" (standing for "Reference") while labels of tests on strengthened elements included the letter "S" (standing for "Strengthened"). Following these markings, for the strengthened elements the abbreviation of the solution and the combination of solutions was used. At the end, a sequence number was added. Thus, the two tests on bare reference elements were denoted as PS-R-01 and PS-R-02, respectively. 

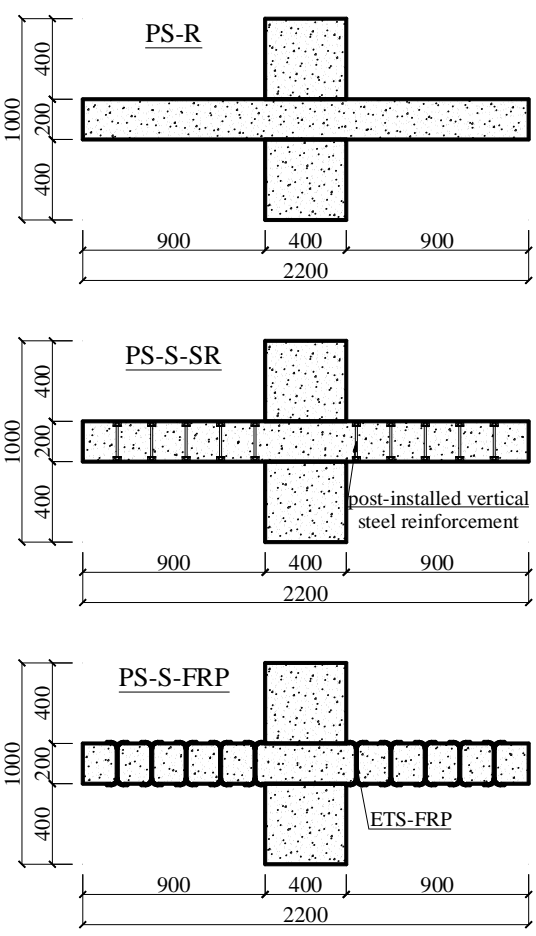

Figure 6. Strengthening solutions and their combination - set 1
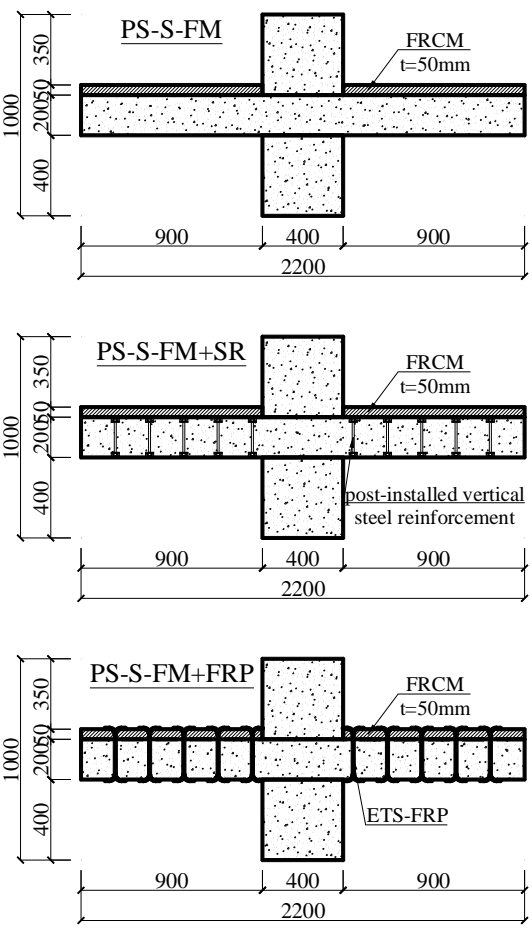

Figure 7. Strengthening solutions and their combinations - set 2
The elements are full scale ones (1:1), having dimensions of $2200 \times 2200 \times 200 \mathrm{~mm}$. On both sides of the slabs, a 400×400x400 $\mathrm{mm}$ block of reinforced concrete was constructed, simulating the columns. For clarity reasons, the blocks will be referred in this paper as "columns". All elements were cast using C25/30 class of concrete. The slabs were reinforced identically at the top and bottom sides using deformed steel rebar $(10 \mathrm{~mm}$ and 14 $\mathrm{mm}$ in diameter with spacing of $150 \mathrm{~mm}$ ). Standard B500C type of steel was used for all rebar. Designed concrete cover to reinforcement was $25 \mathrm{~mm}$. The initial configuration of all twelve slabs was identical in terms of geometry and material specifications and Figure 8).

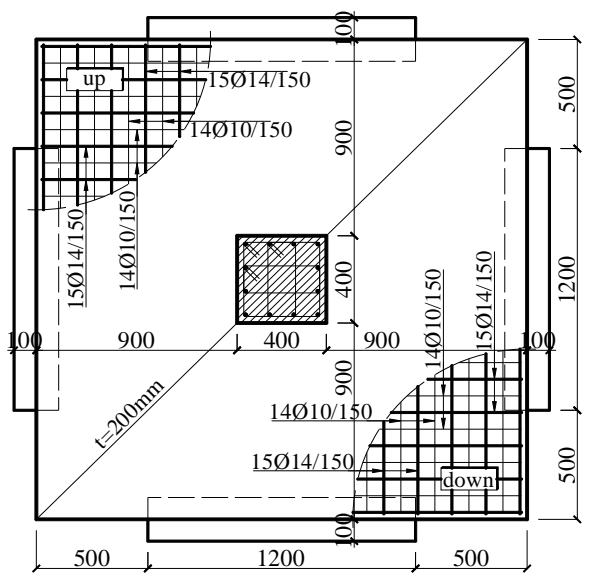

Figure 8. Reinforcement details of all specimens

The specimens were placed horizontally, resting on a series of RC supports and were loaded gravitationally. The slab-support interface was provided by a layer of fresh mortar, the elements settling in horizontal position under own weight. This type of support blocked gravitational displacements while allowing still for uplift of corners and edges of the slabs. With this set-up the bottom side became the tensioned one (as opposed to such slabs in regular structures). The load was applied onto the top short column in controlled increments of $5 \mathrm{kN}$ until full failure. All specimens were tested in undamaged stage (i.e. all strengthening systems will be applied on specimens prior to any tests). The test setup can be observed in Figure 9 through a vertical cross-section and Figure 10 through a $3 \mathrm{D}$ view.

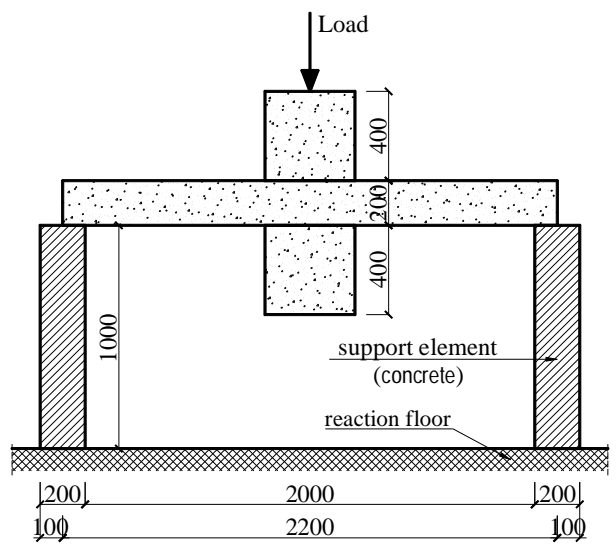

Figure 9. Test set-up - cross-section 


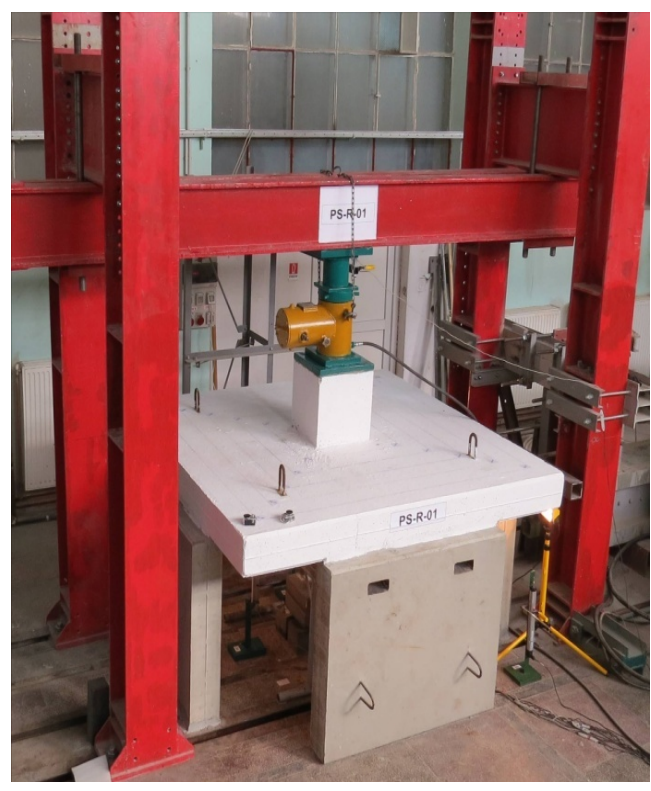

Figure 10. Test set-up - 3D view

\section{RESULTS OF TESTS ON BARE ELEMENTS}

In the case of the two elements, a very predictable behaviour was observed, with a quasi-linear elastic load-displacement diagram and a brittle and sudden failure at ultimate load. Initial behaviour of both elements was virtually identical, with a first stiffness degradation identified at a load value of $100 \mathrm{kN}$ and a central vertical displacement of $0.23 \mathrm{~mm}$ and a second one at a load value of $200 \mathrm{kN}$ and a central vertical displacement of 0.57 $\mathrm{mm}$. A third one is identified at load levels of $300 \mathrm{kN}$, corresponding to vertical displacements of $1.26 \mathrm{~mm}$ and 1.48 $\mathrm{mm}$ for specimens PS-R-01 and PS-R-02, respectively.

Considering load intervals of $100 \mathrm{kN}$, the largest stiffness degradation can be identified at the $200 \mathrm{kN}$ load level, accounting for a loss in stiffness of $63 \%$ for PS-R-01 on the 200-300 kN interval as compared to the stiffness on the 100-200 $\mathrm{kN}$ interval. The loss on this interval for the PS-R-02 specimen only accounts for $51 \%$, as this specimen shows a higher overall stiffness. As it can be observed from the load-displacement diagrams presented in Figure 11, the PS-R-02 displayed also superior strength compared to PS-R-01 (i.e. ultimate loads of $1057 \mathrm{kN}$ for PS-R-02 and $952.5 \mathrm{kN}$ for PS-R-01), although the configuration of specimens, test set-up and test protocol were identical.

Approaching failure, tangential cracks also appeared, at a distance of $100-150 \mathrm{~mm}$ from the edge of the columns, accompanied also by radial cracks connecting the middle of columns edges to the middle of the supporting elements. The final punching failure perimeter appeared at a distance of 50 $\mathrm{mm}$ from the edges of the columns at the top face (in compression) and at an average distance of $300 \mathrm{~mm}$ at the bottom side (in tension). Thus, the angle made by the failure cone's generating line with the directrix varies between $35^{\circ}-45^{\circ}$.

As expected, the failure was sudden, without important previous visual warnings, with a maximum mid-span deflection of 16.7 $\mathrm{mm}$ for PS-R-01 and $15.7 \mathrm{~mm}$ for PS-R-02. The load at which first yielding strain was measured in steel reinforcement (i.e. 0.0025 was considered for the Bst500C steel) was $586 \mathrm{kN}$, corresponding to a maximum central vertical displacement of $5.57 \mathrm{~mm}$. The vertical mid-span displacement has reached maximum allowable deflection in SLS as provided by EN 1992$1-1(\mathrm{~L} / 300=6.67 \mathrm{~mm})$ at a load value of $665 \mathrm{kN}$ (EN 1992-1-1, 2004). The first cracks appeared in a radial shape, oriented from the corners of the column to the corners of the supporting elements. As the loads increase, more radial cracks appear, oriented from the middle of the columns to the corners of the supporting elements, and followed by cracks oriented from the corners of the columns to the corners of the experimental specimen.

The load-displacement diagrams recorded for the bare elements are presented in Figure 11 and the final crack patterns for the two specimens are presented in Figure 12 and Figure 13. The soffit of the PS-R-01 specimen is shown in Figure 12 after posttest mechanical removal of all cracked and loose concrete at the bottom side.

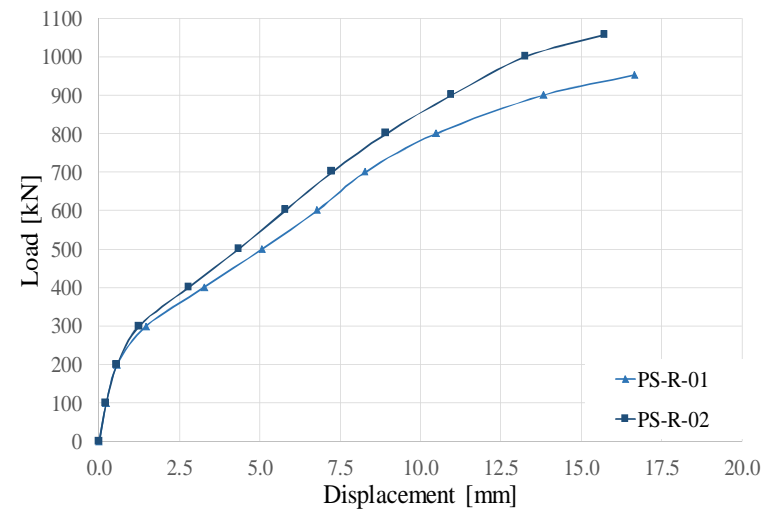

Figure 11. Load-Displacement diagrams of bare elements

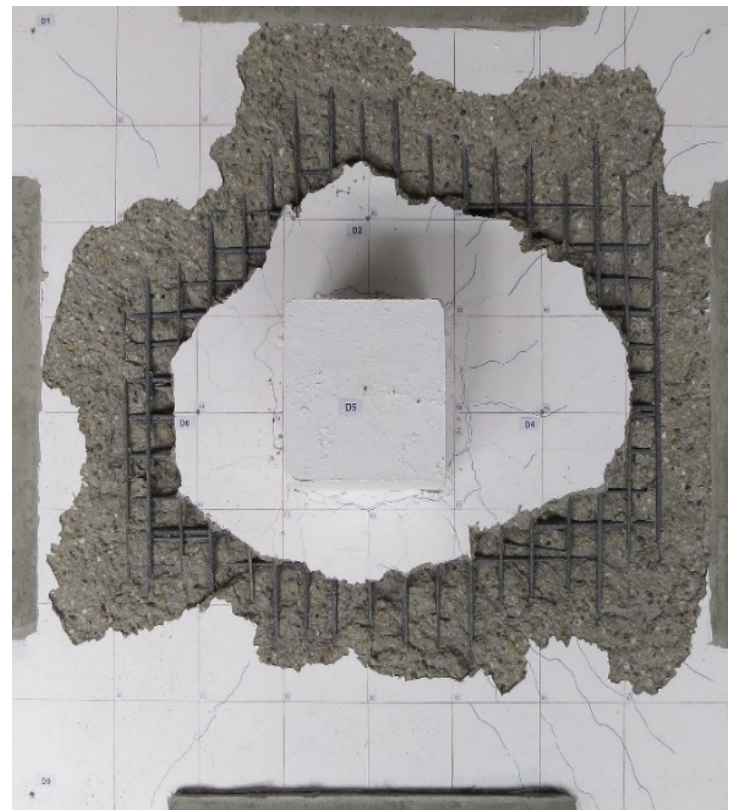

Figure 12. Final crack pattern for specimen PS-R-01 


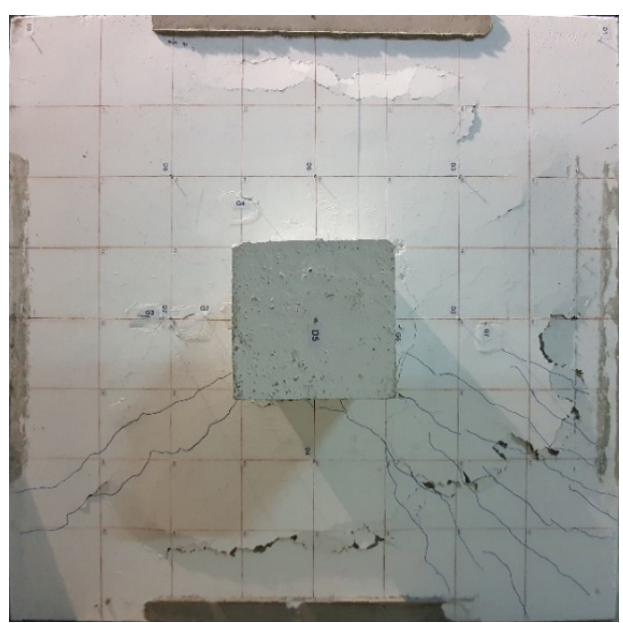

Figure 13. Final crack pattern for specimen PS-R-02

\section{NUMERICAL MODELLING}

The program which was used in order to numerically model the behaviour of the specimens was ATENA 3D (Advanced Tool for Engineering Nonlinear Analysis) developed by Cervenka Consulting (Črvenka, 2017). The 3D view of the full model is shown in Figure 14 and Figure 15.

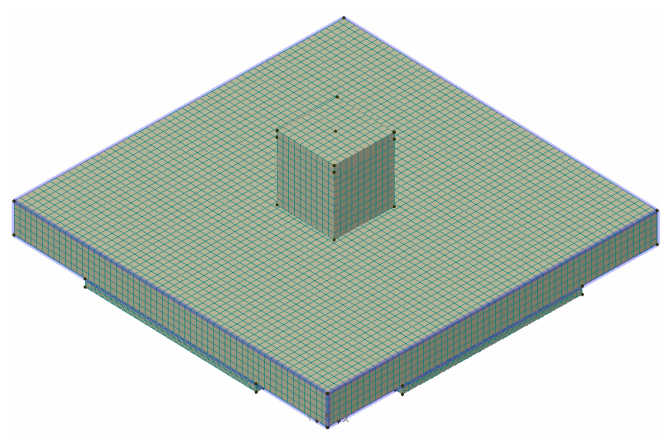

Figure 14. FEM 3D model - top perspective view

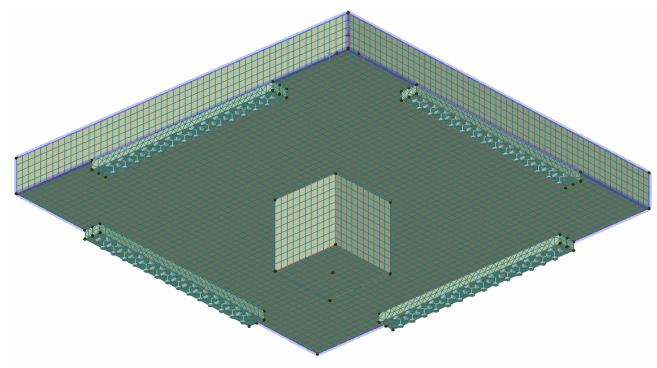

Figure 15. FEM 3D model - bottom perspective view

\subsection{Materials}

Standard material definitions have been utilized, considering "CC3DNonLinCementitious2" material for concrete modelling, with C25/30 class characteristic values. The stress-strain law definition for concrete is presented in Figure 16.

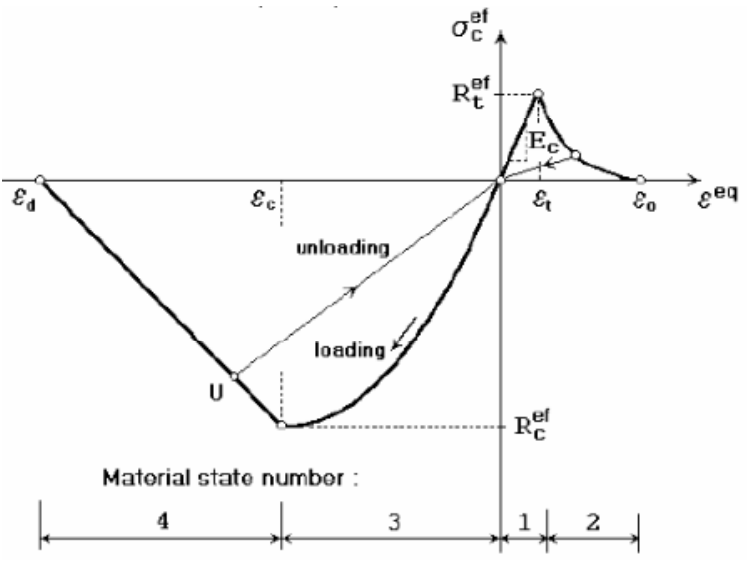

Figure 16. Stress-strain law for concrete (Červenka, 2018)

All reinforcement was modelled using discrete type (by means of linear elements). One type of "CCReinforcement" material type was used (Červenka, 2018), defined by a simplified bilinear stress-strain law without hardening. The materials had the elastic modulus of $208000 \mathrm{MPa}$. The normal reinforcement was defined with an elastic limit of $500 \mathrm{MPa}$. Perfect bond was assumed between reinforcement and concrete. The stress-strain law definition for steel reinforcement is presented in Figure 17.

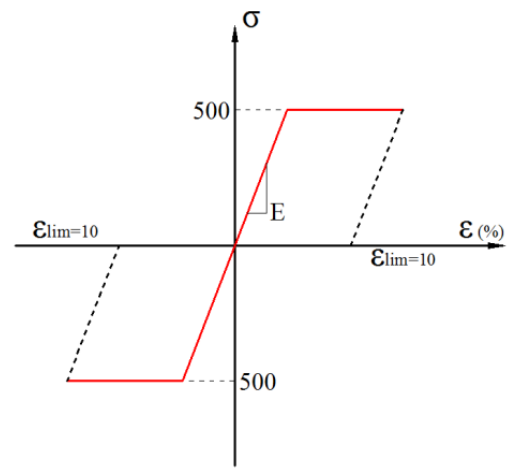

Figure 17. Stress-strain law for steel reinforcement

\subsection{Supports, loads and finite element mesh}

The interfaces between the two concrete blocks simulating the columns and the slab were considered as full bond, while interfaces between the slab and supports were defined using a "3D Interface" material type, simulating the mortar and thus allowing for uplift of slabs (as tensile strength and cohesion are all null). Hexahedral "brick" finite elements were utilized in order to mesh all the modelled macro-elements. The thickness of the slab was divided into 5 meshed layers, with an absolute size of the refinement of 0.04 meters.

\subsection{Results of the numerical models}

The load-displacement diagram obtained numerically (denoted PS-R_N) is presented in Figure18 alongside the one calculated as an average of the two experimental tests (denoted PSR_AVG-01\&02). As is can be seen, the numerical simulation 
shows a very good agreement to the experimental results in terms of stiffness (i.e. initial stiffness and stiffness degradation) and load carrying capacity. The divergence in terms of displacement at maximum recorded load is of $6.9 \%(15.32 \mathrm{~mm}$ numerical vs. $14.25 \mathrm{~mm}$ experimental) while the maximum load diverges by $0.2 \%$ (955kN numerical vs. $952.5 \mathrm{kN}$ experimental) from the minimum value obtained experimentally.

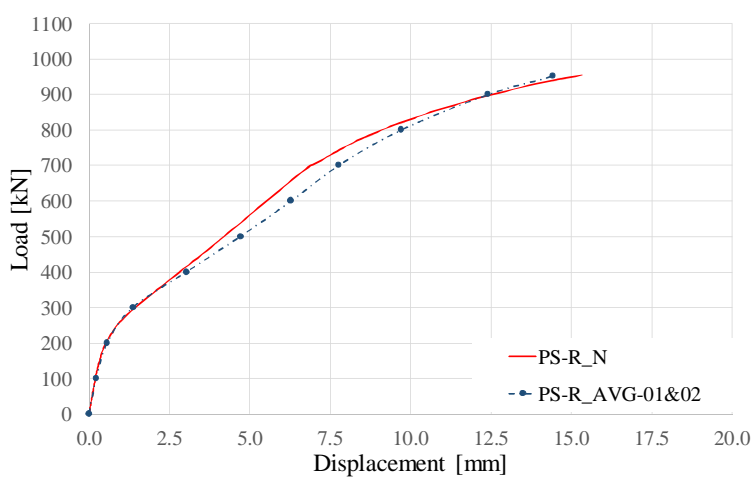

Figure 18. Load-Displacement numerical vs. experimental

The crack pattern obtained in the last stable step of the numerical simulation and the magnified deformed shape of the slab and are shown in Figure 19 and Figure 20, respectively. Figure 19 reproduces only cracks with widths larger than $0.2 \mathrm{~mm}$, while the maximum recorded crack width is $2.5 \mathrm{~mm}$. The similitude to the experimental model is obvious, the critical punching shear perimeter being easily identifiable along with the diagonal cracks developed from the corners of the columns to the edges and corners of the flat slab.

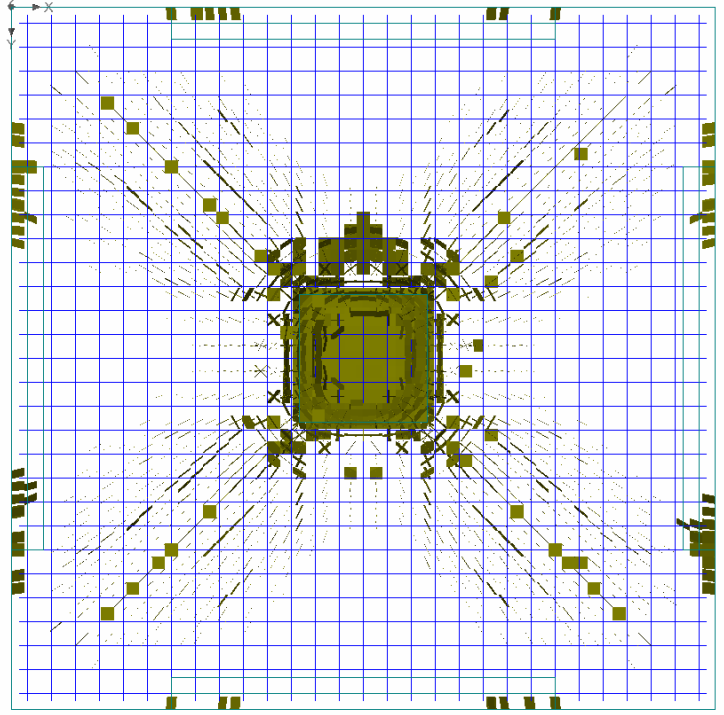

Figure 19. Crack pattern prior to failure - numerical

The deformed shape clearly indicates the capability of the modelled structural element to deform in a coherent manner, with corners being allowed to uplift and with free rotation of the edges.

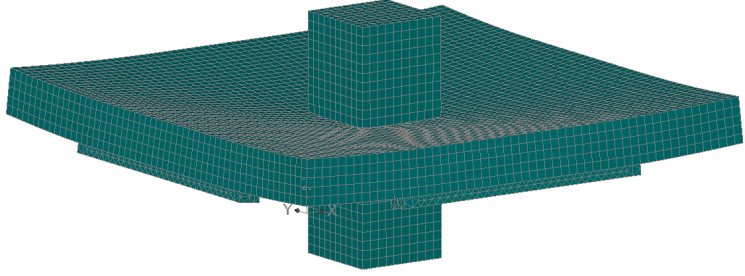

Figure 20. Deformed shape at failure - numerical

\section{ANALYTICAL CALCULATION}

A series of calculations were performed according to provisions in EN 1992-1-1. The critical check for this type of specimens proved to be the one related to the design value of the punching shear resistance of a slab without punching shear reinforcement along the control section considered. Using equation (6.38) in the 2004 version of EN 1992-1-1 (identified below as Equation 1) to determine the shear stress and equation (6.47) of the same norm (identified below as Equations 1 and Equation 2) to determine the design value of the punching shear resistance (as stress, expressed in $\mathrm{MPa}$ ) of a slab without punching shear reinforcement, the capable punching shear force resulted with a value of $350 \mathrm{kN}$. As compared to the minimum value of $952.5 \mathrm{kN}$ obtained experimentally, it could be concluded that for this type of slabs, the code leads to a safety coefficient of more than 2.5 (i.e. 2.72 in this case). While the norm seems quite conservative, the conclusion is valid for the configuration of specimens tested in the current study and should not be extrapolated to design without further research, as design should still encompass a reasonable amount of conservative approach.

$$
v_{E d}=\beta \frac{V_{E d}}{u_{1} d}
$$

where

$$
\begin{aligned}
& v_{E d}=\text { maximum shear stress } \\
& V_{E d}=\text { design shear force } \\
& u_{1}=\text { length of the basic control perimeter } \\
& d=\text { mean effective depth of the slab } \\
& v_{R d, c}=C_{R d, c} k\left(100 \rho_{l} f_{c k}\right)^{1 / 3}+k_{1} \sigma_{c p} \\
& v_{R d, c} \geq v_{\min }+k_{1} \sigma_{c p}
\end{aligned}
$$

where: $\quad v_{R d, c}=$ punching shear resistance without punching shear reinforcement

$$
\begin{aligned}
& C_{R d, c}=\frac{0.18}{\gamma_{c}}=\frac{0.18}{1.5}=0.12 \\
& k_{1}=0.1
\end{aligned}
$$

\section{CONCLUSIONS}

This research aimed to study the behaviour of slab-column connections in RC flat slabs subjected to punching shear. The performances in terms of maximum load carrying capacity and 
stiffness degradation were discussed. At the same time, based on the testing procedure, the progression of cracks, damage and failure modes were highlighted. The following conclusions were drawn based on observations from experimental tests, numerical models and analytical calculations:

- A very predictable behaviour of tested specimens was observed, with a quasi-linear elastic load-displacement diagram and a brittle and sudden failure at ultimate load, without ample previous visual warnings.

- Initial behaviour of both elements was practically identical, with three stiffness degradation stages below the $400 \mathrm{kN}$ load mark.

- Numerical models using standard material definitions available in ATENA showed very good agreement with experimental results in terms of load, deflection and stiffness. The divergence in terms of displacement at maximum recorded load is of $6.9 \%(15.32 \mathrm{~mm}$ numerical vs. $14.25 \mathrm{~mm}$ experimental) while the maximum load diverges by only $0.2 \%$ ( $955 \mathrm{kN}$ numerical vs. $952.5 \mathrm{kN}$ experimental) from the minimum value obtained experimentally.

- Using the EN 1992-1-1 norm leads to a safety coefficient higher than 2.5. While the norm seems quite conservative, the conclusion is valid for the configuration of specimens tested in the current study and should not be extrapolated to design without further research, as design should still encompass a reasonable amount of conservative approach.

\section{ACKNOWLEDGEMENTS}

This work was partially supported by research grant $\mathrm{GNaC} 2018$ - ARUT, no. 1353/01.02.2019, financed by Politehnica University of Timisoara.

\section{References:}

Alexander S.D.B., Simmonds S.H., 1986. Shear-Moment Transfer in Column-Slab Connections. Structural Engineering Report SER 141, Department of Civil Engineering, University of Alberta, pp. 95.

Bartolac M., Damjanovic D., Duvnjak I., 2015. Punching strength of flat slabs with and without shear reinforcement. Gradevinar, 67(8), pp. 771-786.

Červenka V., Červenka J., 2017. ATENA Program Documentation - Part 2-2 - User's Manual for ATENA 3D. Červenka Consulting, Prague, Czech Republic.

Červenka V., Jendele L., Červenka J., 2018. ATENA Program Documentation - Part 1 - Theory. Červenka Consulting, Prague, Czech Republic.

EN 1992-1-1, 2004. Eurocode 2: Design of concrete structures Part 1-1: General rules and rules for buildings. European Committee for Standardization.

Fernández Ruiz M., Muttoni A., 2009. Applications of critical shear crack theory to punching of reinforced concrete slabs with transverse reinforcement. ACI Structural Journal, 106(4), pp 485-494.

Fernandez Ruiz M., Muttoni A., Kunz J., 2011. Strengthening of Flat Slabs Against Punching Shear Using Post-Installed Shear Reinforcement, AICI Structural Journal, 107, pp. 434442.

Furst A., Marti D., 1997. Robert Maillart's Design Approach for Flat Slabs. Journal of Structural Engineering, 123(8), pp. $1102-1110$.

Gardner, N.J., Huh, J., and Chung, L., 2002. Lessons from Sampoong Department Store Collapse. Cement and Concrete Composites, 24(2), pp. 523-529.

Kierdorf A., 2006. Early Mushroom Slab Construction in Switzerland, Russia and the U.S.A. - A Study in Parallel Technological Development. Proceedings of the Second International Congress on Construction History, pp. 17931807.

Kinnunen S., Nylander H., 1960. Punching of Concrete Slabs without Shear Reinforcement. Kungliga Tekniska Hogskolan, Stockholm.

Kunz J., Fernández Ruiz M., Muttoni A., 2008. Enhanced safety with post-installed punching shear reinforcement. Tailor Made Concrete Structures - New Solutions for Our Society, Taylor and Francis Group, pp. 679-684.

Lips, S., Fernández Ruiz, M., Muttoni, A., 2012. Experimental Investigation on Punching Strength and Deformation Capacity of Shear-Reinforced Slabs, ACI Structural Journal, 109, pp. 889-900.

Meisami M.H., Mostofinejad D., Nakamura H., 2013. Punching shear strengthening of two-way flat slabs using CFRP rods. Composite Structures, 99, pp. 112-122.

Muttoni A., Schwartz J., 1991. Behaviour of beams and punching in slabs without shear reinforcement. IABSE Colloquium, Stuttgart, Germany, 62, pp. 703-708.

Muttoni A., 2008. Punching shear strength of reinforced concrete slabs without transverse reinforcement. ACI Structural Journal, 105(4), pp. 440-450.

Popescu D., 2018. Consolidarea zonelor de rezemare a planșeelor dală în vederea sporirii capacității la străpungere (Strengthening of slab-column connection of flat slabs in order to increase punching shear capacity). Masteral Thesis, Politehnica University Timisoara, Timişoara, România.

Portland Cement Association, 2005. An Engineer's Guide to: Economical Concrete Floor Systems. IS063.

Said A.M., Tian Y., Hussein A., 2012. Evaluating punching shear strength of slabs without shear reinforcement using artificial neural networks. International Concrete Abstracts Portal, 287, pp. 1-18.

Westergaard H.M., Slater W.A., 1921. Moments and Stresses in Slabs. Washington, D. C.: National research council. 